\title{
Great wits and madness: more near allied? ${ }^{\dagger}$
}

Kay Redfield Jamison

\begin{abstract}
Summary
A purported association between creativity and psychopathology is ancient, persistent and controversial. Biographical research, studies of living artists and writers, and investigations into the cognitive and temperamental factors linked to both creativity and mood disorders suggest a more specific link to bipolar illness. A new,
\end{abstract}

large and well-designed population-based study adds further support to this connection.

\section{Declaration of interest}

None.
Kay Redfield Jamison is the Dalio Family Professor in Mood Disorders and Professor of Psychiatry at the Johns Hopkins University School of Medicine. She is also Honorary Professor of English at the University of St Andrews in Scotland.

A link between creativity and madness was anciently declared and assumed by many. Others have disagreed, dismissing the purported association as a naive romanticisation of mental illness or a miscomprehension of the diversity of imagination and temperament necessary for original work. Debate is inevitable and will continue, but the results of a large, well-designed study by Kyaga and his associates in this month's Journal give support to accumulating evidence showing a disproportionately high rate of mental illness, especially bipolar disorder, in creative individuals. ${ }^{1}$

\section{Evidence for a link}

Biographical studies of eminent artists and writers have found higher rates of psychosis (predominantly mania), institutionalisation, incapacitating depression and suicide in a wide-range of creative individuals, from poets to jazz musicians. ${ }^{2-5}$ Studies of living artists and writers have found similarly high rates of mood disorders, especially bipolar illness. ${ }^{6-8}$ Both types of studies have been limited by small sample sizes and inconsistency in diagnostic and selection criteria; their results, however, are consistent with converging lines of research linking psychopathology, creativity and high achievement.

Investigators have shown that familial patterns of mental illness and creativity exist as well. Forty years ago, Icelandic researchers found that individuals with psychosis, as well as their first-degree relatives, were far more likely than the general population to be eminent in artistic and intellectual endeavours. ${ }^{9}$ (The patients, described by the investigators as 'schizophrenics', in more recent years have been re-categorised as having had affective illness.) A later study of writers, $80 \%$ of whom met the diagnostic criteria for depression or bipolar illness, found that the first-degree relatives of the writers were more likely to have mood disorders than were the relatives of the controls; they also

'See pp. 373-379, this issue were more likely to have histories of creative accomplishment. ${ }^{6}$ Harvard researchers, in a study of non-eminent individuals, found higher creativity scores in individuals with bipolar and cyclothymic disorders, as well as their normal first-degree relatives, than among the controls. ${ }^{10}$

Further evidence for an association between bipolar illness and high achievement was found in a prospective, 10-year, whole-population cohort study of all individuals in the Swedish national school register $\left(n=713876\right.$ after exclusions). ${ }^{11}$ Those who demonstrated excellent school performance were nearly four times as likely to develop bipolar illness as were those who showed only an average level of performance. Excellence in language or music was particularly correlated with an increased risk for developing bipolar disorder. Schizophrenia was associated with a decreased risk for excellence.

Two other large studies have addressed a different pattern of association, one between creative occupation and psychopathology. The first, an analysis of interview data collected from more than 20000 participants in the Epidemiologic Catchment Area Study, found that individuals with bipolar illness were disproportionately concentrated in the most creative occupational categories. ${ }^{12}$ This finding is consistent with the more recent and differently designed Swedish investigation reported in this month's Journal. Kyaga and his colleagues conducted a nested case-control study using Swedish total population registers in order to examine the relationship between mental illness and occupation. ${ }^{1}$ The likelihood of being in a creative occupation was compared in individuals who had been hospitalised for schizophrenia, bipolar disorder or unipolar depression, their non-diagnosed relatives and controls. Although having a creative occupation is not the same thing as being creative, the study is large and the inferences from it are strong.

People with bipolar disorder were overrepresented in the creative professions; this was not true for those with schizophrenia or unipolar depression (although individuals with schizophrenia had an increased rate in the artistic subgroup). Additionally, first-degree relatives of people with bipolar disorder and schizophrenia, but not unipolar depression, were more likely than controls to hold creative jobs.

The researchers examined rates of creative occupations in non-affected half-siblings of patients who shared either a mother or a father; no significant differences were found. This, coupled with the finding that the likelihood of creative occupations decreased with increasing familial distance to the patients, led the authors to suggest that genetic rather than 
environmental factors were more likely to explain the cosegregation of creativity and psychopathology. This is consistent with earlier familial studies of mental illness and creativity. ${ }^{6,9,10}$ Not surprisingly, many researchers have suggested that some features of bipolar illness and schizophrenia may confer adaptive advantage to the affected individuals and/ or their relatives. ${ }^{2,10,13,14}$ Whatever the genetic and environmental mechanisms for this may be they are complex and will be addressed most decisively by neuroimaging, genetic and neuropsychological research. ${ }^{15,16}$

The lack of association between unipolar depression and creative occupation is seemingly inconsistent with studies that have found an elevated rate of depression in artists, writers and composers. $^{2-8}$ This may reflect the underreporting of mild manic states, as well as diagnostic confusion (for example, the complex relationship between bipolar illness, major depressive illness and recurrent depression, and the lack of clarity in differentiating major depression manifested by rapid thinking, agitation and irritability from bipolar illness, or mixed states from agitated depression.) $)^{17}$

It would seem counterintuitive that a painful, not infrequently lethal illness such as bipolar disorder should be associated with creativity. It would seem particularly odd in the light of the substantial and well-documented neuropsychological deficits that often accompany it, such as impaired concentration, short-term memory deficits and impaired executive function. ${ }^{17}$ But other mood, cognitive, behavioural, energy and temperament factors associated with bipolar disorder can enhance creativity. Elevated mood and rapidity of thought, for example, often facilitate creative work; mania and hypomania have been shown to increase associational fluency ${ }^{18-20}$ and combinatory thinking, ${ }^{21}$ both of which are important in creativity. Non-cognitive aspects of bipolar illness - for example, risk-taking, grandiosity, restlessness and discontent, illness-induced introspection and a need to make meaning of, or to ameliorate suffering - exert an influence on imagination and creativity as well. The overlap between the bipolar and creative temperaments has been studied and discussed at length. ${ }^{2,22}$

\section{Ethical and clinical implications}

No one would argue that there is a straightforward relationship between psychopathology and creativity. Most people who are creative do not have mental illness and most people who are mentally ill are not unusually creative. It is, rather, that there is a disproportionate rate of psychopathology, especially bipolar disorder, in highly creative individuals. A link exists and this will prove to have important ethical, scientific and clinical implications. Genetic testing for bipolar illness is inevitable. Increasingly sophisticated prenatal selection techniques will give new options to those at risk for passing on the illness. This may result in the unintended consequence of selecting against potentially beneficial variance in cognitive styles, drive, risk-taking and temperament. The potential for misuse through the development of pharmacological or other techniques to enhance cognition, energy, and mood can be imagined. Related to this, it is essential to develop treatments that minimise the adverse effects of medication on positive aspects of mood disorders. Bipolar illness is devastating and this should remain the central focus of our scientific and clinical work. But while doing so, we need to keep in mind the anciently observed thin partitions between disease and imagination.

Kay Redfield Jamison, PhD, Department of Psychiatry, Meyer 3-181,

The Johns Hopkins Hospital, 600 North Wolfe St, Baltimore, MD 21287, USA Email: kjamiso1@jhmi.edu

First received 21 Jul 2011, accepted 11 Aug 2011

\section{References}

1 Kyaga S, Lichtenstein $\mathrm{P}$, Boman $\mathrm{M}$, Hultman $\mathrm{C}$, Långström $\mathrm{N}$, Landén $\mathrm{M}$. Creativity and mental disorder: family study of 300000 people with severe mental disorder. Br J Psychiatry 2011; 199: 373-9.

2 Jamison KR. Touched With Fire: Manic-Depressive IIIness and the Artistic Temperament. Free Press, 1993.

3 Schildkraut JJ, Hirshfeld AJ, Murphy JM. Mind and mood in modern art, II: Depressive disorders, spirituality, and early deaths in the abstract expressionist artists of the New School. Am J Psychiatry 1994; 151: 482-8.

4 Post F. Creativity and psychopathology. A study of 291 world-famous men. Br J Psychiatry 1994; 165: 22-34.

5 Ludwig AM. The Price of Greatness: Resolving the Creativity and Madness Controversy. Guilford Press, 1995.

6 Andreasen NC. Creativity and mental illness: prevalence rates in writers and their first-degree relatives. Am J Psychiatry 1987; 144: 1288-92.

7 Jamison KR. Mood disorders and patterns of creativity in British writers and artists. Psychiatry 1989; 52: 125-34.

8 Ludwig AM. Mental illness and creative activity in female writers. Am J Psychiatry 1994; 151: 1650-6.

9 Karsson JL. Genetic association of giftedness and creativity with schizophrenia. Hereditas 1970; 66: 177-82.

10 Richards R, Kinney DK, Lunde I, Benet M, Merzel AP. Creativity in manic-depressives, cyclothymes, their normal relatives, and control subjects. J Abnorm Psychol 1988; 97: 281-8.

11 MacCabe JH, Lambe MP, Cnattingius S, Sham PC, David AS, Reichenberg A, et al. Excellent school performance at age 16 and risk of adult bipolar disorder: national cohort study. Br J Psychiatry 2010; 196: 109-15.

12 Tremblay $\mathrm{CH}$, Grosskopf S, Yang K. Brainstorm: occupational choice, bipolar illness and creativity. Econ Hum Biol 2010; 8: 233-41.

13 Wilson DS. Adaptive genetic variation and human evolutionary psychology. Ethol Sociobiol 1994; 15: 219-35.

14 Brod JH. Creativity and schizotypy. In Schizotypy: Implications for IIIness and Health (ed GS Claridge): 276-98. Oxford University Press, 1997.

15 Keller MC, Miller G. Resolving the paradox of common, harmful, heritable mental disorders: which evolutionary genetic models work best? Behav Brain Sci. 2006; 29: 385-404.

16 Keri S. Genes for psychosis and creativity: a promoter polymorphism of the neuregulin 1 gene is related to creativity in people with high intellectual achievement. Psychol Sci 2009; 20: 1070-3.

17 Goodwin FK, Jamison KR. Manic-Depressive Illness: Bipolar Disorders and Recurrent Depression. Oxford University Press, 2007.

18 Henry GM, Weingartner H, Murphy DL. Idiosyncratic patterns of learning and word association during mania. Am J Psychiatry. 1971; 128: $564-74$.

19 Pons L, Nurberger Jl, Murphy DL. Mood-independent aberrancies in associative patterns in bipolar disorder: an apparent stabilizing effect of lithium. Psychiatry Res 1985; 14: 315-22.

20 Levine J, Schild K, Kimhi R, Schreiber G. Word associative production in affective versus schizophrenia psychoses. Psychopathology 1996; 29: 7-13.

21 Solovay MR, Shenton ME, Holzman PS. Comparative studies of thought disorders: I. Mania and schizophrenia. Arch Gen Psychiatry 1987; 44: 13-20.

22 Santosa CM, Strong CM, Nowakowska C, Wang PW, Rennicke CM, Ketter TA. Enhanced creativity in bipolar disorder patients: a controlled study. J Affect Disord 2007; 100: 31-9. 